\title{
PRESENSI KARYAWAN BERBASIS APLIKASI MOBILE DENGAN FILTER JARINGAN INTRANET DAN IMEI
}

\author{
${ }^{1}$ Agung Sasongko, ${ }^{2}$ Muhammad Sony Maulana, ${ }^{3}$ Latifah \\ Program Studi Sistem Informasi, Fakultas Teknologi Informasi, Universitas Bina Sarana Informatika \\ Jalan Abdurahman Saleh No.18A Pontianak \\ Email: agung.ako@bsi.ac.id, Muhammad.sony.mom@bsi.ac.id, latifah.lat@bsi.ac.id
}

(Diterima: 8 September 2019, direvisi: 4 Desember 2019, disetujui: 8 Desember 2019)

\begin{abstract}
Discipline control through presence must be carried out by the Bina Sarana Informatika University (UBSI) Foundation which has more than 40 campuses and is spread across five provinces with a total number of employees more than 3000. Currently, the recording of attendance is done using web technology which is named Kampus.id. It is implemented by using an internet connection by building a VPN network tunnel that connects the central campus with regional campuses. The development of communication technology such as Android and iOS-based smart devices has made UBSI innovate to create effective and efficient presence applications. The utilization of a mobile application for employee attendance is developed while maintaining proper monitoring management. One way to reduce the element of attendance recording manipulation that can occur on the web is to impose rules, namely the presence can only be done on the campus intranet network. The smartphone device used as a presence must have registered its IMEI and paired with the Employee Master Number on the campus.id system. Hence the authentication system applies one user active on one device at a time. From the results of this test, a mobile system can be more efficient than a web system because employees do not need to queue on a presence computer which is limited in number because they can make a presence on an intelligent telephone device and the results of this presence activity find an attendance server response on average 0.83 seconds.
\end{abstract}

Keywords: mobile applications, IMEI, presence, VPN, web technology

\begin{abstract}
ABSTRAK
Pengendalian displin melalui presensi mesti dilakukan oleh Yayasan Universitas Bina Sarana Informatika (UBSI) yang memiliki lebih dari 40 kampus dan tersebar di lima provinsi dengan jumlah karyawan lebih dari 3000 orang. Saat ini pencatatan kehadiran yang dilakukan menggunakan teknologi web yang diberi nama kampus.id. Kampus.id diimplementasikan secara intranet dengan membangun tunnel jaringan VPN yang menghubungkan antara kampus pusat dengan kampus-kampus wilayah. Berkembanganya teknologi komunikasi seperti perangkat telepon cerdas berbasis Android maupun iOS membuat UBSI berinovasi menciptakan aplikasi presensi yang efektif dan efisien. Pemanfaatan aplikasi mobile untuk presensi karyawan dikembangkan, dengan tetap menerapkan manajemen pemantauan yang benar. Salah satu cara untuk mengurangi unsur manipulasi pencatatan kehadiran yang bisa terjadi pada web maka diberlakukan aturan, yaitu presensi hanya dapat dilakukan pada jaringan intranet kampus. Perangkat telepon cerdas yang digunakan sebagai presensi harus sudah didaftarkan IMEI-nya dan disandingkan dengan Nomor Induk Karyawan pada sistem kampus.id, sehingga sistem otentikasi berlaku satu pengguna hanya bisa aktif pada satu perangkat dalam satu waktu. Dari hasil pengujian ini sistem mobile dapat lebih efisien dari sistem web dikarenakan karyawan tidak perlu melakukan antrian di komputer presensi yang jumlahnya terbatas karena dapat melakukan proses presensi di perangkat telpon cerdasnya dan hasil kegiatan presensi ini mendapati respons server presensi rata-rata 0.83 detik.
\end{abstract}

Kata kunci: aplikasi mobile, imei, presensi, vpn, teknologi web 


\section{PENDAHULUAN}

Kegiatan pencatatan kehadiran oleh karyawan Yayasan Bina Sarana Informatika (UBSI) saat ini dilakukan melalui aplikasi web yang bernama kampus.id yang dapat diakses dari komputer yang terhubung pada jaringan intranet kampus. Pada pelaksanaannya, selain harus mengantri bila trafik terlalu tinggi maka waktu tanggap sistem menjadi lebih lama, sehingga akan menyebabkan karyawan yang mengantri dapat tercatat datang terlambat. Karena bukan hanya harus menunggu antrian tetapi respons sistem yang kadang melambat, sedangkan waktu terus berjalan.

Sistem pencatatan kehadiran yang tengah berjalan saat ini memungkinkan karyawan untuk melakukan manipulasi dengan cara bekerja sama antar karyawan dalam bentuk saling mengabsenkan. Karena proses pencatatan kehadiran karyawan pada kampus.id dapat dilakukan dengan memasukkan Nomor Induk Karyawan dan kata sandi masuk ke sistem, Jadi siapapun yang mengetahui informasi tersebut akan dapat mencatat kehadiran karyawan lainnya.

Solusi penggunaan fingerprint sebagai alat presensi untuk menghindari upaya manipulasi di tiap kantor dirasa memiliki kendala yaitu penarikan data kehadiran dari setiap mesin fingerprint yang berada di-setiap kantor dan di semua wilayah, serta harus disinkronkan ke dalam sistem informasi kehadiran yang telah dimiliki dari sisi Divisi Sumber Daya Manusia yang ada di kantor pusat. Penanganan yang lebih panjang prosedurnya, sehingga dirasa kurang tepat. Oleh karenanya sistem kehadiran yang dipilih untuk digunakan pada kantor di dalam dan diluar wilayah pusat menggunakan sistem berbasis web, selain karena lebih mudah dalam implementasinya, juga karena faktor biaya yang lebih efisien.

Tujuan dari penelitian ini untuk mengembangkan sebuh rancangan sistem presensi yang yang lebih mudah diimplementasikan oleh Yayasan Bina Sarana Informatika dimana secara demografi kampus-kampus berada pada lokasi wilayah yang berjauhan dengan kondisi satu server yang terpusat dengan meminimalisir upaya manipulasi kegiatan presensi yang dapat dilakukan oleh orang lain. Maka penulis mgembangkan sistem presensi berbasis aplikasi mobile, yang dapat mendukung keamanan presensi, manajemen presensi dan memudahkan karyawan untuk mengetahui jumlah keterlambatan maupun ketidak hadiran pada suatu periode.

\section{TINJAUAN PUSTAKA}

\section{A. Aplikasi Mobile}

Aplikasi mobile atau perangkat berpindah dalam bahasa Indonesianya merupakan piranti lunak yang dijalankan pada piranti keras yang memiliki sifat layanan bergerak[1] . Pada dasarnya aplikasi mobile dikembangkan pada lapisan kerangka kerja, umumnya aplikasi lain seringkali langsung beroperasi pada level sistem operasi.

\section{B. Presensi}

Presensi adalah suatu kegiatan mencatat kehadiran[2]. Jadi presensi karyawan dimaksudkan agar perusahaan dapat mencatat dan memonitoring kehadiran karyawan.

\section{RestFul Web}

Representational State Transfer (REST) adalah standar arsitektur yang menetapkan batasan komunikasi didalam pengembangan layanan berbasis web, seperti antarmuka yang seragam, yang jika diterapkan pada layanan web dapat menginduksi properti sesuai dengan pola yang diinginkan, seperti kinerja, skalabilitas, dan kemampuan modifikasi, yang memungkinkan memberikan layanan terbaik di Web[3] .

Ada empat prinsip dasar utama yang melandasi Metode REST, yaitu [3]:

1. Identifikasi sumber daya melalui URI ( Uniform Resource Identifier),

2. Uniform Interface, dengan cara memanipulasi CRUD (Create, Read, Update, Delete) menggunakan standar operasi HTTP yaitu PUT, GET, POST, DELETE.

3. Selft-descriptive message, sumberdaya informasi mandiri sehingga tidak terkait yang lain, sehingga dapat mengakses berbagai format konten (HTML, PDF, JPEG, XML, Plain Text dan lainnya).

4. Stateful interaction thtough hyperlink, setiap interaksi dengan suatu sumberdaya bersifat stateless, yaitu request message tergantung jenis kontennya.

\section{Jaringan Virtual Private Network (VPN)}

Jaringan Virtual Private Network (VPN) merupakan jaringan yang menggunakan infrastruktur internet untuk menghubungkan antara 2 kampus atau 2 kantor yang terpisah secara virtual. Biasanya 
digunakan untuk mendukung akses keamanan dalam menyediakan remote akses untuk perkantoran atau individu dengan akses yang aman ke dalam jaringan perusahaan/instansi. Adanya VPN dapat meringankan perusahaan dalam pembiayaan menyediakan jaringan khusus bagi perusahaan/instansi dengan kemampuan yang sama dengan IP Public, tetapi dengan biaya yang jauh lebih rendah. [4]

E. Framework Aplikasi Mobile Multi Platform

Kerangka kerja (framework) Aplikasi Mobile Multi Platform merupakan rangkaian software yang bisa dijalankan di mobile operating system yang berbeda-beda seperti Android, iOS dan Windows Phone.[5]

Transofrmasi pencatatan kehadiran untuk menekan upaya manipulasi dapat diupayakan dari berbasis web ke aplikasi berbasis telepon pintar. Hasil data yang dikutip dari katadata.co, menunjukkan jumlah pengguna telepon pintar di Indonesia tiap tahunnya mengalami peningkatan, mulai dari tahun 2016 yang tercatat 65.2 juta pengguna, 2017 tercatat 74,9 juta, tahun 2018 tercatat 83.5 juta dan di tahun 2019 tercatat 92 juta pengguna telepon pintar[6]. Dikutip pula dari data yang dikeluarkan oleh StatCounter per April 2019, share market jumlah pengguna telepon genggam cerdas di indonesia adalah pengguna Android 93.5\% dan iOS 5.22\%, dan sisanya 1.33[7]. Dari data diatas menunjukkan bahwa jumlah pemilik telepon pintar telah banyak, dan semua karyawan telah memilikinya. Dengan cara presensi dilakukan pada perangkat telepon pintar masing-masing karyawan, sehingga dari sisi penerapan biaya yang dikeluarkan tidak akan menjadi besar. Dari sisi teknologi, berdasarkan jumlah pengguna perangkat cerdas dan sistem operasinya pengembangan aplikasi yang lebih dominan yaitu berbasis Android dan IOS.

Beda antara aplikasi desktop/web dengan aplikasi mobile adalah aplikasi mobile dapat dikembangkan menggunakan framework, sedangkan aplikasi lain berjalan secara langsung di atas Sistem Operasi. Sistem operasi Android merupakan sistem operasi yang terdiri dari lapisan-lapisan sistem operasi berbasis Linux, seperti: Android Runtime dan Application Framework [8] . Arsitektur android berupa 4 lapisan [9] diantaranya: Lapisan pertama merupakan kernel Linux sebagai lapisan yang paling dekat dengan mesin, lapisan ini dapat mengatur perangkat keras. Lapisan kedua merupakan Libraries dan Android Runtime, lapisan ini terdiri dari direktori pustaka-pustaka untuk mengelola perangkat keras serta Android Runtime sebagai inti dari Sistem Operasi Android yang menggunakan sistem Virtual Dalvik Machine. Lapisan ketiga merupakan Application Framework, yaitu bagian kerangka kerja dari aplikasi-aplikasi yang akan dijalankan diatasnya, dan Lapisan keempat merupakan semua aplikasi yang dapat berjalan di Android.

Penelitian terdahulu yang dilakukan oleh Agung Sasongko, Latifah dan Rabiatul Adwiyah pada Jurnal Edukasi dan Penelitian Informatika (JEPIN) Vol 4 No. 2 tahun 2018 dengan judul Perancangan Prototipe Aplikasi Mobile Tazkirah menyebutkan bahwa aplikasi mobile memiliki tingkat waktu tanggap yang relatif lebih cepat daripada aplikasi berbasis web, disebabkan oleh komunikasi data yang dilakukan dengan format JSON yang cenderung lebih efisien dari HTML[10].

Penelitian yang dilakukan oleh Al Husain dan Prastian pada jurnal Technomedia Journal (JTML) Vol 2 No.1 Agustus 2017 dengan judul Perancangan Sistem Informasi Absensi Online Menggunakan Android Guna Mempercepat Proses Kehadiran Karyawan Pada PT. Sintech Berkah Abadi melaporkan bahwa presensi secara online berbasis Android harus digunakan pada jaringan lokal kantor untuk menghindari karyawan dapat melakukan presensi diluar kantor. Kegiatan presensi menggunakan perangkat telepon pintar milik sendiri lebih memudahkan dan mempercepat karyawan dalam pencatatan kehadirannya saat tiba di kantor[11].

Penelitian yang dilakukan oleh Jun Iio pada prosiding yang dimuat pada $19^{\text {th }}$ International Conference on Network-based Information System dengan judul Attendance Management System using a Mobile device and a web application, dalam tulisannya melaporkan penggunaan framework Novel atau Sistem Manajemen Kehadiran Novel. Sebelumnya cara presensi mahasiswa foto diri dan mengirimkan tanda tangan, namun dianggap kurang efektif, dan cara diganti yaitu presensinya mahasiswa dengan mengambil gambar chameleon code yang ditampilkan di ruang kelas. Chameleon code yang dikabarkan lebih baik dari pada QR-Code[12].

Penelitian lain dilakukan oleh Agustin dalam artikel yang berjudul Perancangan Web Portal Pada Jaringan Intranet (Study Kasus : Stmik Potensi Utama), pada dasarnya jaringan intranet merupakan istilah bagi jaringan lokal yang dikembangkan berdasarkan teknologi internet dengan tetap memanfaatkan protocol TCP/IP didalamnya. Konsep pembangunan jaringan ini diperuntukkan untuk menjalankan sistem lokal yang lebih aman, sehingga sumber daya hanya dapat diakses dari dalam. 
Tujuannya adalah membuat kinerja akses sistem lebih cepat, lebih aman, dan lebih hemat tentunya. Dengan memanfaatkan jaringan intranet yang telah dibangun, tentunya sistem yang dikembangkan akan lebih mudah dipantau tingkat kestabilannya dan tidak harus bergantung kepada provider jasa layanan internet. Terutama untuk sistem yang hanya dibutuhkan di dalam area kampus saja, sehingga tidak diperlukan adanya jaringan internet. Selain itu web portal berfungsi untuk menguji sistem informasi yang masih dalam tahap pengembangan oleh programmer[13].

Sulastri dkk dalam artikel yang berjudul Server-Side Processing Techniques For Optimizing The Speed Of Presenting Big Data merupakan alur server-side processing, ketika menggunakan pemrosesan sisi server, browser akan membuat permintaan Ajax baru ke server untuk setiap permintaan data yang diminta. Permintaan ini kemudian dikodekan ke format JSON yang akan mengirimkan respon dari script DataTables AJAX. Sehingga permintaan load data akan terasa ringan dikarenakan data akan melakukan request perhalaman ketika akan di tampilkan di web browser [14].

\section{METODOLOGI PENELITIAN}

Penelitian dilakukan dengan pengembangan perangkat lunak yang akan digunakan dalam bentuk pendekatan purwarupa (prototype) yang dilakukan secara bertahap kepada calon pengguna[15]. Hal ini bertujuan untuk mendapatkan gambaran aplikasi presensi mobile yang dapat diterapkan di lingkungan yayasan Bina Sarana Informatika.

Sumber: (Mulyani, 2016)

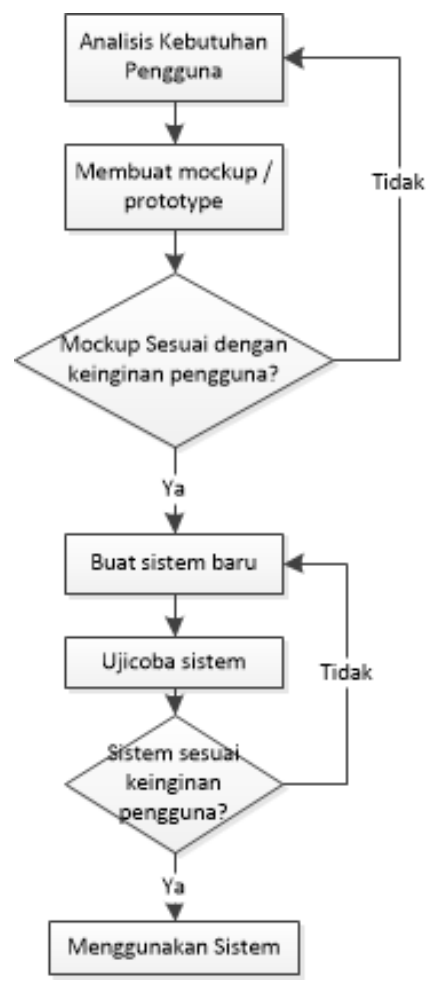

\section{Gambar 1 Langkah-langkah prototipe}

Langkah-langkah membuat prototipe aplikasi digambarkan pada Gambar 1.

1) Analisa kebutuhan sistem, yaitu kebutuhan fungsional dan non fungsional sistem dijabarkan dalam langkah pertama.

2) Membuat mockup/prototype, kemudian pembuatan mockup dilakukan berdasarkah hasil analisa kebutuhan sistem.

3) Analisa hasil mockup, apakah mockup yang sudah dibuat hasilnya sesuai dengan hasil analisa kebutuhan pengguna, jika sesuai maka dilanjutkan ketahap berikutnya jika tidak sesuai maka kembali melakukan analisa kebutuhan sistem.

4) Membuat sistem baru, hasil mock up yang sudah dianalisa kemudian dilanjutkan menjadi sistem. 
5) Ujicoba sistem, pada langkah ini sebuah sistem harus melalui tahapan ujicoba sebelum masuk ke tahapan penggunaan sistem, jika terjadi ketidaksesuaian antara keinginan penguna dengan sistem maka sistem harus dibuat ulang jika tidak maka sistem akan diterapkan.

\section{A. Use Case Diagram}

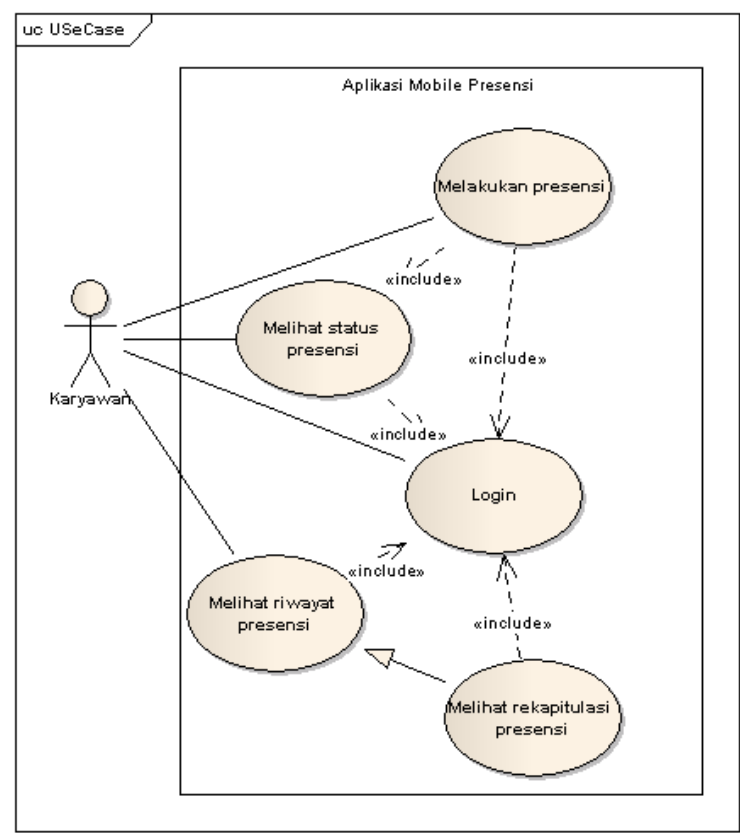

Sumber: (Hasil Rancangan, 2019)

\section{Gambar 2 Use case diagram aplikasi mobile presensi}

\section{B. Bagan Class Model}

Bagan class-model untuk menunjukkan bentuk struktu data yang akan dikelola oleh aplikasi dalam bertukar informasi ke server.

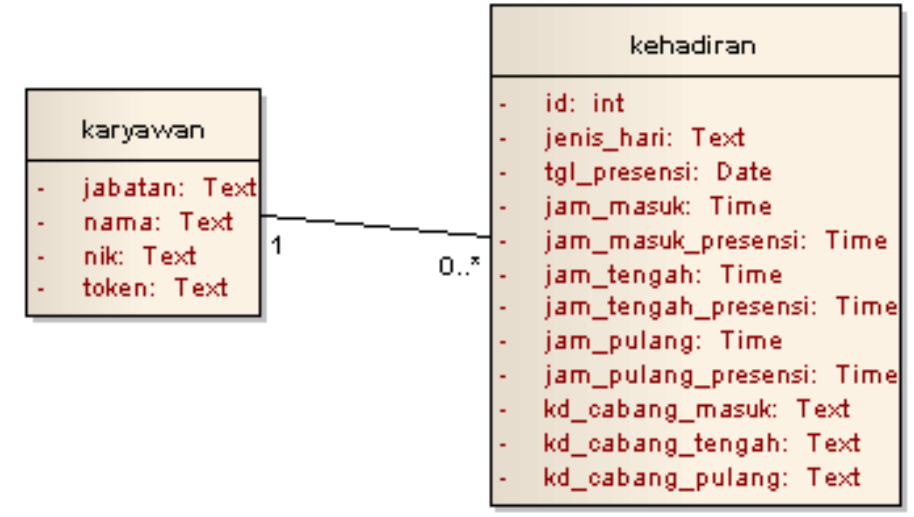

Sumber: (Hasil Rancangan, 2019)

C. Bagan Aktifitas login

\section{Gambar 3 Class model}

Login merupakan langkah awal agar aplikasi dapat mengakses informasi lebih dalam dari server mengenai data presensi karyawan. Selain mengetahui kesesuaian antara NIK dan sandi karyawan di database server, aktifitas login untuk mendapatkan Token Otentikasi dari server. Token ini yang akan selalu digunakan setiap transaksi data antara aplikasi mobile ke server agar memastikan satu perangkat satu akun. Terlihat pada gambar 4 . 


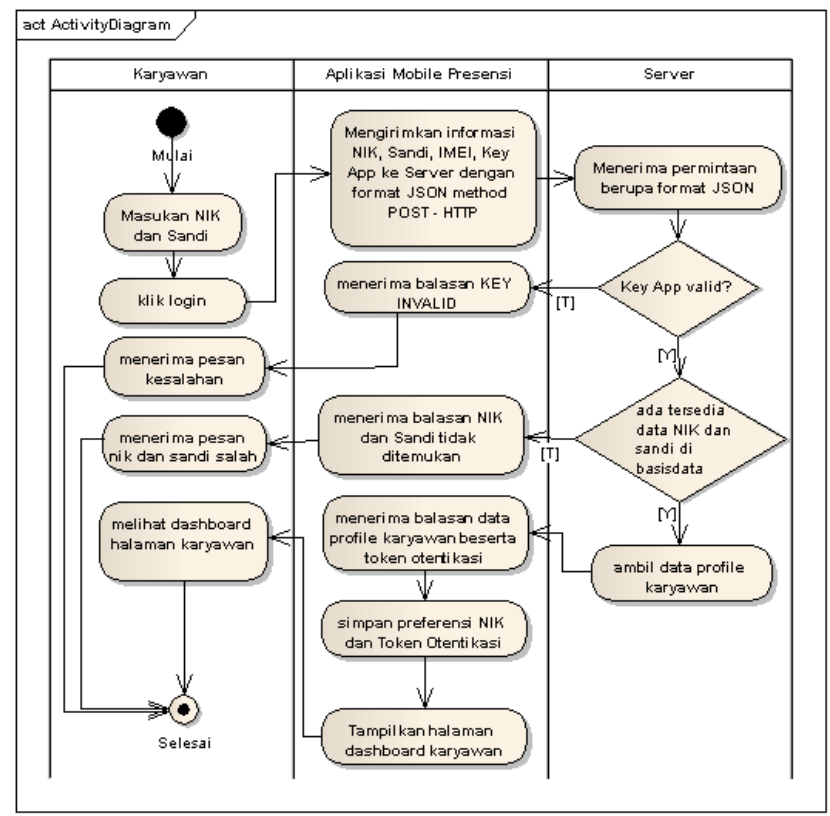

Sumber: (Hasil Rancangan, 2019)

\section{Gambar 4 Aktifitas login}

\section{Prosedur Presensi}

Presensi adalah suatu kegiatan mencatat kehadiran [2]. Jadi presensi karyawan dimaksudkan agar perusahaan dapat mencatat dan memonitoring kehadiran karyawan.

Langkah-langkah kerja aplikasi mobile presensi.

1. Aplikasi mobile meminta ke server api.Kampus.id jadwal presensi yang harus dilakukan pada hari terkini berupa tanggal presensi, jam masuk, jam tengah dan jam pulang serta lokasi kantor saat masuk, tengah dan pulang.

2. Server akan melakukan validasi berupa kesesuaian token, NIK dan IMEI yang ada di basis data di server dengan yang dikirimkan oleh aplikasi mobile, bila sesuai kemudian akan mengirimkan balik informasi jadwal presensi karyawan berupa format JSON, berisikan : tanggal, jam masuk, jam tengah, jam pulang dan lokasi kantor harus masuk, tengah dan pulang. Serta jam terkini dari server.

3. Aplikasi mobile menerima tanggapan dari server, bila tanggapan berupa invalid, maka aplikasi menampilkan informasi bahwa perangkat harus dilakukan sinkronisasi ke server dengan mendaftarkan IMEI ke sistem Kampus.id. Apabila pesan dari response berupa jadwal presensi karyawan, maka aplikasi akan menghitung jam harus presensi dengan jam terkini. Jam terkini yang berlaku adalah jam dari server. Bila sudah menunjukkan masuk waktu harus presensi, maka menampilkan informasi "Masuk", bila belum masuk waktu maka aplikasi menampilkan waktu mundur menuju waktu presensi.

4. Bila karyawan melakukan presensi saat sebelum masuk waktu, maka aplikasi akan konfirmasi terlebih dahulu, karena presensi memperbolehkan karyawan untuk pulang awal, dan pada sisi sistem di divisi SDM akan tercatat sebagai pulang awal yang akan mempengaruhi penilaian kedisiplinan karyawan tersebut.

5. Bila presensi dilakukan maka aplikasi akan mengirimkan informasi ke server yang berkaitan dengan informasi di sisi karyawan, yaitu Nomor induk karyawan, lokasi IP karyawan berada, informasi MAC Address perangkat, dan juga token. Server akan menanggapi kemudian mencatat di basisdata presensi kemudian mengirimkan informasi balik berupa catatan di server mengenai kondisi kehadiran karyawan pada hari itu juga.

6. Bagian riwayat kehadiran pada sisi aplikasi mobile presensi, menarik data riwayat kehadiran dari sisi server per tanggal 24 bulan lalu hingga tanggal 23 bulan terkini.

7. Rekapitulasi kehadiran merupakan perhitungan rekap dari bagian riwayat kehadiran yang menghitung jumlah hari masuk tepat waktu, jumlah hari terlambat, tidak sesuai shift dan jumlah hari tidak masuk. Perhitungan hari masuk kerja berdasarkan nilai pada attribut 
jenis_hari, bila jenis_hari adalah "Hari Kerja" maka dihitung, bila selain itu maka tanggal presensi tidak akan dihitung. Terhitung tepat waktu apabila karyawan masuk minimal 1 jam sebelum waktu jam masuk dan pulang maksimal 1 jam setelah jam pulang seharusnya. Karyawan dihitung tidak sesuai shift bila karyawan masuk diluar jam seharusnya masuk namun masuk minimal 1 jam sebelum jam masuk pada jadwal shift masuk lainnnya dan pulang maksimal 1 jam setelah jam pulang shift lainnya.

E. Bagan infrastruktur jaringan di setiap kantor wilayah.

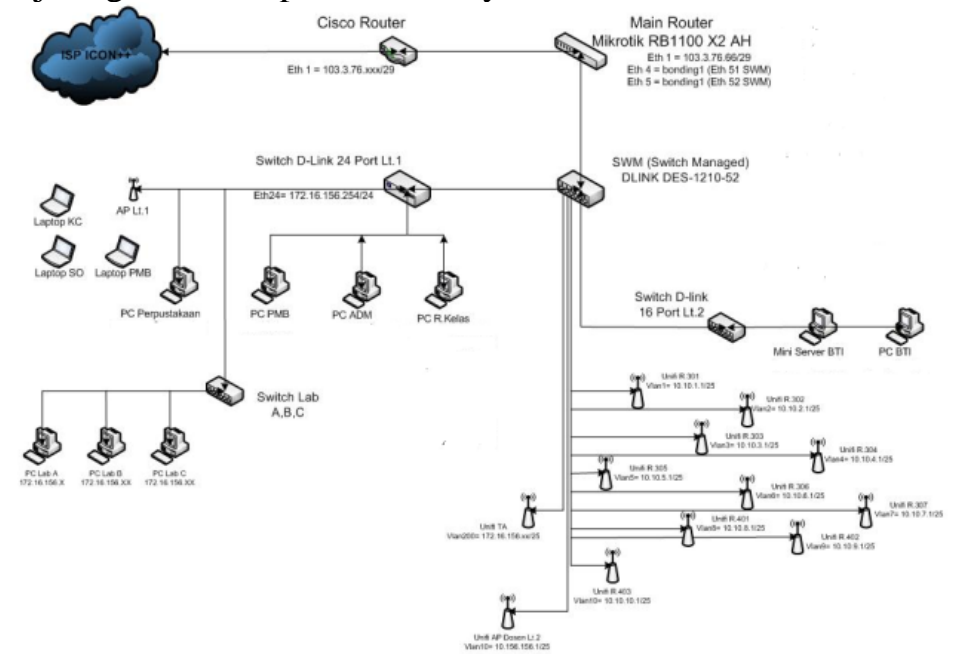

Sumber: (Hasil Rancangan, 2019)

\section{Gambar 5 Topologi jaringan kampus PSDKU}

Berdasarkan gambar 5 diatas bahwa jaringan di kampus utama maupun kampus PSDKU terdiri dari LAN dan WLAN. Untuk WLAN sendiri terbagi sesuai dengan ruangan tempat unit bekerja. Setiap router dari kampus PSDKU akan terhubung secara VPN dengan router di kampus utama sehingga akses data ke dalam server tetap dianggap intranet meskipun berbeda wilayah.

F. Bagan Penerapan Sistem Informasi

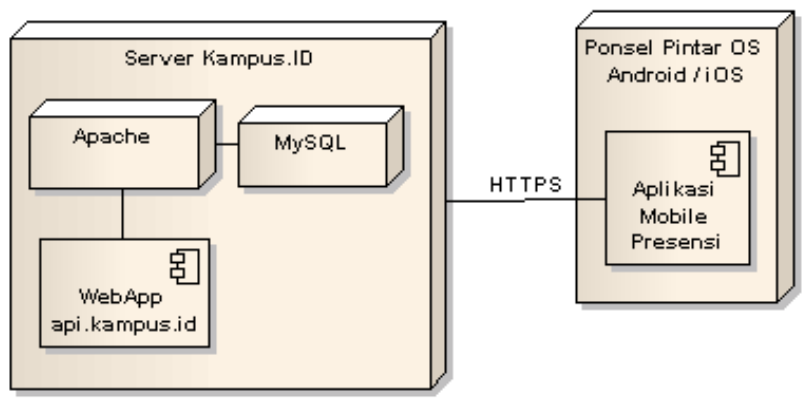

Sumber: (Hasil Rancangan, 2019)

\section{Gambar 6 Deployment system}

Pada Gambar 6, server kampus.id tidak hanya menjalankan service Apacahe dan MySQL tetapi juga menjalankan API (Appication Programming Interface) kampus.id sehingga ponsel pintar akan mengambil data berdasarkan yang tersaji di API, dengan begitu dapat memfilter data-data apa saja yang perlu ditampilkan dan data-data apa saja yang tidak perlu ditampilkan.

\section{HASIL DAN PEMBAHASAN}

Hasil dari penelitian ini didapatkan bahwa kebutuhan fungsional aplikasi dan kebutuhan non fungsional aplikasi diantaranya:

A. Kebutuhan Fungsional Aplikasi Mobile Prsesnsi 
1. Otentikasi masuk ke aplikasi mobile menggunakan Nomor Induk Karyawan (NIK) dan sandi yang terdaftar pada sistem informasi akademik. Setelah otentikasi berhasil aplikasi mendapatkan token dari server yang harus disimpan pada preferensi perangkat telpon pintar.

2. Membaca ID mesin (IMEI) pada perangkat yang menggunakan aplikasi kemudian selalu dikirimkan ke server setiap kali berkomunikasi data. IMEI (International Mobile Equipment Identity) merupakan suatu nomor unik yang dimiliki oleh setiap perangkat mobile yang dapat dijadikan sebagai identitasnya [16]

3. Mendapatkan informasi jadwal presensi yang harus dilakukan oleh karyawan dari server Kampus.id, untuk menunjukkan kepada karyawan kapan waktu presensi yang harus dilakukan.

4. Mengirimkan informasi kegiatan presensi yang dilakukan oleh karyawan berupa Alamat mesin jaringan (MAC Address) perangkat telepon pintar karyawan, alamat Internet Protocol (IP), nomor induk karyawan, dan token otentikasi.

5. Mendapatkan riwayat kegiatan presensi yang telah dilakukan karyawan.

6. Mengetahui rekapitulasi yang menghitung jumlah hari presensi, jumlah hari terlambat dan jumlah hari tidak masuk kerja.

7. Memastikan satu perangkat satu akun. Yaitu dengan cara selalu mengirimkan nomor induk karyawan, dan token otentikasi setiap berkomunikasi permintaan data ke server.

B. Kebutuhan non-Fungsional Aplikasi Mobile Presensi

1. Aplikasi Mobile presensi dirancang untuk dapat diakses oleh seluruh karyawan Yayasan Bina Sarana Informatika selama jam kerja dan berada di kantor, maka penerapan aplikasi ini harus dalam jaringan lokal (intranet) UBSI yang telah dikonfigurasi terhubung secara tunnel ke jaringan kantor pusat..

2. Aplikasi presensi dapat berjalan semua perangkat mobile baik berbasis Android maupun iOS.

3. Jenis Komunikasi data harus efisien dalam penggunaan bandwidth dan proses pengembangan aplikasi berbiaya rendah.

4. Jenis komunikasi harus menggunakan jaringan aman terenkripsi untuk menghindari pencurian data di dalam jaringan.

Sedangkan untuk mock up hasil dari penelitian ini tampilan awal aplikasi presensi dapat dilihat pada gambar 7. Aplikasi presensi terletak pada aplikasi M-Staff Universitas Bina Sarana Informatika, sehingga bisa diakses melalui internet maupun intranet. Khusus untuk presensi harus terhubung melalui jaringan intranet kampus UBSI agar sesuai dengan peta absensi yang sudah diplot untuk setiap karyawan.

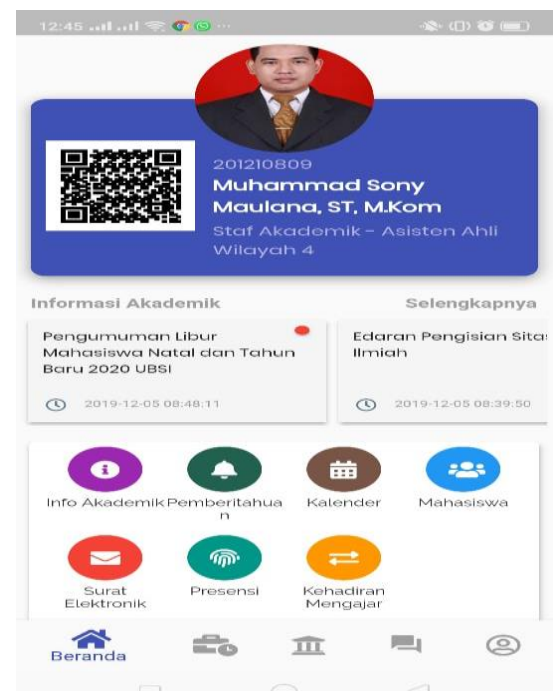

\section{Gambar 7 Tampilan beranda pada m-staff ubsi}

Didalamnya terdapat menu Presensi yang apabila diklik maka aplikasi dapat membedakan pengguna berdasarkan IMEI, jika IMEI yang belum terdaftar maka presensi kehadiran tidak dapat dilakukan. Proses 
pembacaan data juga dapat berjalan dengan sempurna ketika ponsel pintar terhubung kedalam jaringan intranet kampus. Jika bukan dari jaringan intranet kampus atau menggunakan jaringan seluler serta IMEI belum didaftarakan, aplikasi mobile akan mendeteksi bahwa ponsel pintar tersebut bukan didalam jaringan kampus yang ditunjukkan pada gambar 8 . Hal ini sangat perlu mengingat kedisiplinan waktu dan keamanan proses presensi memang harus terhubung dengan wifi atau jaringan intranet kampus, sehingga tidak bisa melakukan presensi dari mana saja..
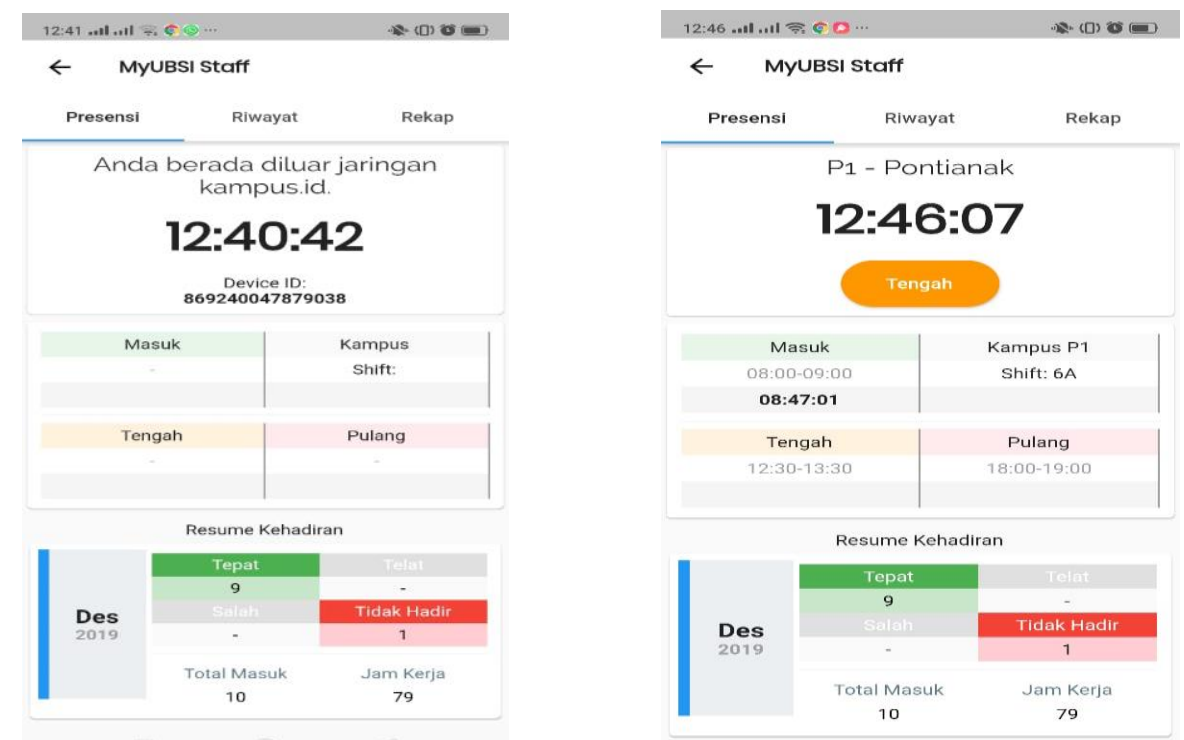

Gambar 8 Tampilan presensi karyawan

Pada menu presensi diatas terdapat tiga menu presensi yaitu, presensi untuk melakukan absensi karyawan yang terbagi menjadi 3 bagian waktu (masuk, tengah dan pulang dimana proses absensi harus sesuai dengan peta absensi dari jam kerja karyawan yang telah ditetapkan oleh SDM. Menu riwayat untuk melihat rekap absensi karyawan per hari jika ada yang tidak sesuai waktu presensi atau telat melakukan presensi maka dianggap 'Salah" dan akan terlihat pada gambar 9.
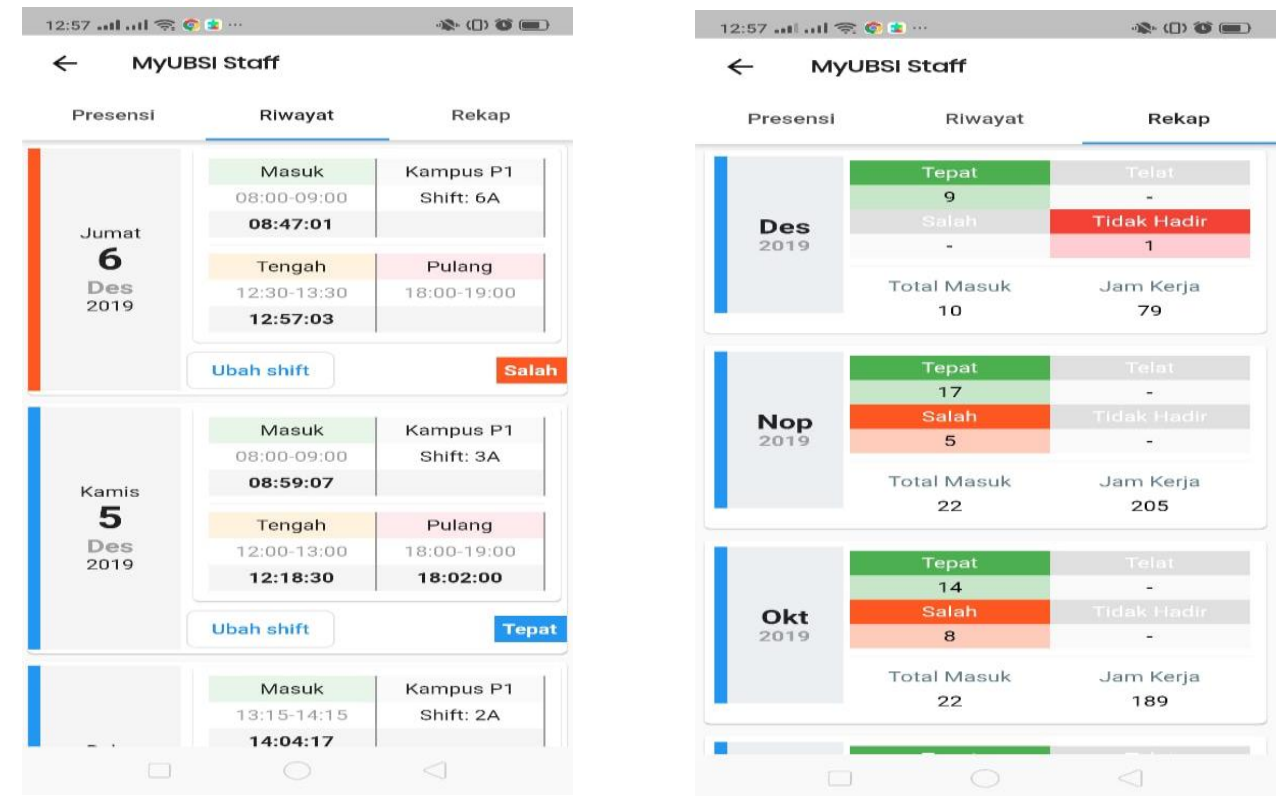

Gambar 9 Tampilan riwayat dan rekap presensi karyawan 
Untuk menu riwayat sendiri menyajikan data riwayat presensi karyawan dan dapat dilihat per bulan, yang merekap data kehadiran karyawan perbulannya dengan menampilkan jumlah masuk, jumlah tepat waktu dan jumlah salah presensi. Sebagaimana yang ditunjukkan oleh gambar 9.

Berikut ini uji kecepatan dan pengukuran aplikasi dalam memuat data dengan menggunakan format JSON.

Tabel 1 Uji Kecepatan Aplikasi Memuat Data.

\begin{tabular}{|c|l|c|}
\hline $\begin{array}{c}\text { No } \\
\cdot\end{array}$ & \multicolumn{1}{|c|}{ Variabel } & $\begin{array}{c}\text { Waktu } \\
\text { (milisecon } \\
\text { d) }\end{array}$ \\
\hline 1 & $\begin{array}{l}\text { Rata-rata load json } \\
\text { slot absensi }\end{array}$ & 0.87 \\
\hline 2 & $\begin{array}{l}\text { Rata-rata load json } \\
\text { kirim absensi }\end{array}$ & 0.79 \\
\hline 3 & $\begin{array}{l}\text { Rata-rata load json } \\
\text { riwayat absensi }\end{array}$ & 0.82 \\
\hline
\end{tabular}

Berdasarkan uji kecepatan aplikasi yang telah dilakukan pada Tabel 1, menunjukkan bahwa proses memuat data dengan format JSON membutuhkan waktu rata-rata 0.83 milisecond. Sehingga dapat disimpulkan kinerja sistem sudah cukup baik dan optimal dalam merespon smartphone (ponsel pintar). Dan fitur-fitur keamanan juga berfungsi seperti filter IMEI dan filter jaringan Wifi kampus yang ditunjukkan pada gambar 8 .

\section{KESIMPULAN}

Berdasrkan pembahasan diatas, dapat disimpulkan bahwa penerapan presensi kehadiran karyawan dengan mengusung konsep presensi melalui jaringan intranet dapat dilakukan dengan baik melalui pembacaan IMEI dan pembatasan jaringan lokal untuk melakukan presensi. Hal ini dapat mempermudah karyawan dalam melakukan presensi dan memudahkan lembaga dalam mnerapkan manajemen presesnsi serta dapat diterapkan pada kampus yang tersebar dibanyak wilayah dengan berbeda demografi. Rekap absensi antara kampus utama dengan kampus wilayah dapat dijalankan melalui jaringan VPN yang terpasang di masing-masing router. Sehingga sangat efektif dalam perekapan dan pemantauan kinerja karyawan. Berdasarkan hasil uji, waktu memuat data yang berjenis JSON dari aplikasi mobile dapat diakses dalam waktu akses rata-rata 0.83 milisecond, sehingga tidak ada hambatan dalam penerapan aplikasi ini secara luas.

\section{UCAPAN TERIMA KASIH}

Penulis mengucapkan terima kasih kepada seluruh tim jurnal Sistemasi yang telah membantu terbitnya paper ini terutama kepada reviewer dan tim editor yang telah melakukan review dan editing naskah paper ini sehingga artikel ini dapat terbit.

\section{DAFTAR PUSTAKA}

[1] F. Sari, Metode Dalam Pengambilan Keputusan. Yogyakarya: Budi Utama, 2018.

[2] "No Title," Kamus Besar Bahasa Indonesia. 2019.

[3] F. N. Rofiq and A. Susanto, "Implementasi RESTful Web Service untuk Sistem Penghitungan Suara Secara Cepat pada Pilkada," pp. 159-168.

[4] M. S. Maulana, "Pemanfaatan Redmine, Subversion Dan Hamachi Sebagai Manajemen Proyek Sistem Informasi Pada Jaringan Vpn,” LPPM BSI Jakarta, vol. XIV, no. 2, pp. 211-223, 2012.

[5] P. Dewanti, P. Adi, and G. Permana, "Pengembangan Aplikasi Hybrid Menggunakan Ionic 2 Framework dan Angular 2," pp. 396-400, 2017.

[6] Katadata.co.id, "Pengguna Smartphone di Indonesia 2016-2019," 2018.

[7] Statcounter.com, "No Title," Mobile Operating System Market Share Indonesia Apr 2018 Apr 2019, 2019. [Online]. Available: https://gs.statcounter.com/os-marketshare/mobile/indonesia. 
[8] A. Sasongko, "Dan Teknologi Komputer Integrasi Data Website Students . Bsi . Ac . Id Untuk Mobile Infokampus Berbasis Android Menggunakan," Sasongko Agung, vol. 2, no. 2, pp. 146$155,2017$.

[9] J. Khan and S. Shahzad, "Android Architecture and Related Security Risks," Asian J. Technol. Manag. Res., vol. 05, pp. 2249-892, 2015.

[10] A. Sasongko, R. Adwiya, and L. Latifah, "Perancangan Prototipe Aplikasi Mobile Tadzkirah," J. Edukasi dan Penelit. Inform., vol. 4, no. 2, pp. 197-203, 2018.

[11] A. Husain, A. H. A. Prastian, and A. Ramadhan, "Perancangan Sistem Absensi Online Menggunakan Android Guna Mempercepat Proses Kehadiran Karyawan Pada PT. Sintech Berkah Abadi," Technomedia J., vol. 2, no. 1, pp. 105-116, 2017.

[12] J. Iio, "No Title," in Attendance Management System Using a Mobile Device and a Web Application, 2016.

[13] F. Agustin, "Perancangan Web Portal Pada Jaringan Intranet ( Study Kasus : Stmik Potensi Utama )," pp. 309-313, 2014.

[14] H. Sulastri, A. Rahmatulloh, and D. K. Hidayat, "Server-Side Processing Techniques for Optimizing the Speed of Presenting Big Data," J. Pilar Nusa Mandiri, vol. 15, no. 1, pp. $47-$ 52, 2019.

[15] S. Mulyani, Metode Analisis dan Perancangan Sistem. Bandung: Abadi Sistematika, 2016.

[16] A. Fanggidae and T. P. Yulianto, "Sistem Presensi Dosen Menggunakan IMEI dan GPS Smartphone dengan Data Terenkripsi," JNTETI, vol. 5, no. 3, pp. 1-8, 2016. 